\title{
The use and modification of injury prevention exercises by professional youth soccer teams
}

\author{
J. O'Brien ${ }^{1}$, W. Young ${ }^{1,2}$, C. F. Finch ${ }^{1}$ \\ ${ }^{1}$ Australian Collaboration for Research into Injury in Sport and Its Prevention (ACRISP), Federation University Australia, \\ Ballarat, VIC, Australia, ${ }^{2}$ Faculty of Health, Federation University Australia, Ballarat, VIC, Australia \\ Corresponding author: James O'Brien, MASc, Australian Collaboration for Research into Injury in Sport and its Prevention \\ (ACRISP), Federation University Australia, SMB Campus, PO Box 663, Ballarat, VIC 3353, Australia. \\ E-mail: ja.obrien@federation.edu.au
}

Accepted for publication 2 August 2016

\begin{abstract}
The efficacy of injury prevention exercise programs (IPEPs) for amateur youth soccer has been established, but little is known about their adaptability to other soccer populations. This study aimed to assess the use of individual injury prevention exercises by professional youth soccer teams, against the industry-standard, FIFA 11+ program. Four teams' chosen IPEPs were observed across one season and documented on a standardized form. The use of each FIFA 11+ exercise was coded as "performed", "performed modified" or "not performed". The proportion of the 160 observed sessions containing each individual exercise was calculated. Staff provided reasons for their use and modification of FIFA 11+ exercises. On average,
\end{abstract}

individual FIFA 11+ exercises were conducted in original form in $12 \%$ of the sessions (range $0-33 \%$ ), and in modified form in $28 \%$ of sessions (range $2-62 \%$ ). The five most frequently observed exercises, in either original or modified form, were "bench" (72\%), "squats" (69\%), "running straight" (68\%), "single-leg stance" (66\%), and "sideways bench" (64\%). Staff modified exercises to add variation, progression, and individualization, and to align with specific training formats and goals. Professional youth soccer teams often use injury prevention exercises similar to those in the FIFA 11+, but tailor them considerably to fit their implementation context.
In view of soccer's world-wide popularity and high injury rates, the development of evidence-based strategies to prevent soccer injuries is of paramount importance (Bizzini et al., 2013). In 2006, the Fédération Internationale de Football Association (FIFA) teamed with two sports injury prevention research centres to develop the FIFA $11+$, a basic injury prevention exercise program aimed at amateur soccer players (Bizzini \& Dvorak, 2015). The results of large-scale randomized controlled trials (RCTs) have since supported the efficacy of the FIFA 11+ in teams of amateur female (Soligard et al., 2008), amateur male (Owoeye et al., 2014), and collegiate male soccer players (Silvers-Granelli et al., 2015). Other injury prevention exercise programs (IPEPs) for amateur soccer, including the Knäkontroll (Waldén et al., 2012) and Prevent Injury Enhance Performance (Mandelbaum et al., 2005), also have demonstrated efficacy. However, recent research highlights

This is an open access article under the terms of the Creative Commons Attribution-NonCommercial-NoDerivs License, which permits use and distribution in any medium, provided the original work is properly cited, the use is non-commercial and no modifications or adaptations are made. that, in addition to establishing efficacy, achieving adequate compliance to IPEPs plays a key role in their ultimate success (Soligard et al., 2010; Hägglund et al., 2013; Steffen et al., 2013).

As support for the FIFA 11+'s efficacy grows (Al Attar et al., 2016), researchers have also explored the program's adaptability to other soccer populations, including veteran (Hammes et al., 2015), children (Rössler et al., 2016), and professional youth teams (O'Brien \& Finch, 2016a). In a cluster RCT of the FIFA $11+$ in veteran players (minimum age of 32), Hammes et al. (2015) found no preventive effect of the FIFA $11+$ on overall injuries. The authors attributed this lack of effect to the low frequency of performed sessions and suggested modifying the program (e.g., adding more ball-based and individual exercises) to better fit the specific implementation context. In recent cross-sectional surveys within professional soccer settings (O'Brien \& Finch, 2016a, b), players and staff members also emphasized the need to adapt IPEPs to their specific context. The survey respondents emphasized the need for adequate exercise variation, progression, individualization, and soccer-specificity. 


\section{O'Brien et al.}

The importance of understanding the context in which an intervention is to be delivered has been highlighted in recent injury prevention implementation research (Padua et al., 2014; Twomey et al., 2015; Donaldson et al., 2016), as well as in established injury prevention models (Finch, 2006; Finch \& Donaldson, 2010). Information on the delivery of IPEPs in professional soccer settings is scarce, but it is known that professional soccer teams strongly support the use of IPEPs and employ similar exercise components (e.g., strength, balance, core stability, and plyometrics) as in established amateur programs, such as the FIFA 11+ (McCall et al., 2014; O'Brien et al., 2016). It is also known that achieving adequate adoption and compliance to injury prevention programs can be challenging in these settings (Bahr et al., 2015).

Professional players, as defined by FIFA (Fédération Internationale de Football Association 2007) earn more than the expenses they occur for soccer activities and have written contracts with a club. In addition to their top-level teams, professional clubs also support youth teams, based in development academies (Price et al., 2004). To date, injury prevention in these professional youth players has received very little research attention (O'Brien \& Finch, 2016b), despite knowledge that physiological loads, psychological loads, and injury rates are very high in these settings (Price et al., 2004; Brink et al., 2010). Reported injury incidences in this population range from 2.0 to 19.4 injuries per 1000 hours, with a recent systematic review finding a higher incidence of training injuries in professional youth players, compared to their adult counterparts (Pfirrmann et al., 2016). In comparison, the reported injury rate in amateur male soccer players ranges from 0.8 to 8.5 injuries per 1000 hours (Junge et al., 2002; Owoeye et al., 2014).

The injury prevention landscape in professional clubs differs to that of amateur soccer clubs in terms of training frequency and staffing. Professional teams typically train on an almost daily basis, compete both nationally and internationally, and are supported by large multi-disciplinary teams including soccer coaches, fitness coaches, and physiotherapists. It has been reported that professional teams adapt injury prevention programs to fit their specific context (O'Brien et al., 2016), which aligns with findings from amateur soccer (Lindblom et al., 2014; Frank et al., 2015) and Australian Football (Fortington et al., 2015; Twomey et al., 2015) settings. Unfortunately, there is a paucity of published information exploring exactly how, and why, teams modify individual exercises to fit their specific settings. For example, the fact that professional soccer teams strongly support the use of eccentric strengthening exercises (McCall et al., 2014), but rarely use the evidence-based (and FIFA 11+ advocated) hamstring lowers exercise (Bahr et al., 2015), raises the question of which alternate exercises they do perform and why. This information is necessary to guide the design and successful delivery of future IPEPs, specifically tailored to the professional soccer context. Accordingly the aims of this present study were:

1. To assess the injury prevention exercises used by professional youth soccer teams, against the industry standard program for amateur soccer, the FIFA $11+$.

2. To report the reasons for use, and modification, of individual exercises by professional youth soccer teams

The findings are expected to inform the development of future IPEPs, specifically tailored to the context of professional youth soccer.

\section{Materials and methods}

This study was a secondary analysis of a prospective observational study. The selection of participants and data collection methods have been previously reported (O'Brien et al., 2016) and are summarized below. However, the original analysis did not address the use and modification of individual exercises, or the reasons for these modifications, which are the focus of this present paper. The study was approved by the Federation University Australia Human Research Ethics Committee and all participants completed informed consent forms.

\section{Participants}

The participants were the soccer coaches, fitness coaches, and physiotherapists from four youth male teams, in a European professional soccer academy. The academy was selected due to existing connections to the researchers. The consent rate was $90 \%$ (18 of 20 eligible staff members). All participants were familiar with the FIFA 11+ program from taking part in a previous survey focussing on injury prevention exercise programs and, more specifically, the FIFA 11+ (O'Brien \& Finch, 2016a). Furthermore, the primary analysis identified fitness coaches as the primary deliverers of IPEPs in this context, with support from physiotherapists (O'Brien et al., 2016). The teams ranged from Under-15 to Under-23 age groups and typically trained 6-7 times/week in addition to playing a game. The majority of players attended school in addition to their soccer activities.

\section{Data collection}

On a weekly basis, across the entire 2014/2015 soccer season, one injury prevention exercise session from each of the four teams was observed by one author (J. O.) and documented on a standardized data collection sheet (O'Brien et al., 2016). To achieve a balance in the number of observations at different time points across the training week, a block randomization method was used, whereby one injury prevention session from the total number of scheduled sessions in the week (as provided by team staff) was selected for observation. When block randomization was compromised (e.g., short-term cancellation of the selected session), one of the remaining sessions in the week was chosen at random using an online generator (www.random.org). Ninety percent of the planned observations were completed (160 of 168) and eight observations were missed due to short-term cancellation by the team staff or the observer being absent (e.g., illness, educational leave). 


\section{Data collection sheet}

During each observation, the team's use of each individual FIFA 11+ exercise (Fédération Internationale de Football Association 2016) was coded as either "performed", "performed modified", or "not performed". Exercises were considered modified when progressions or equipment, other than those outlined in the original FIFA 11+ (Fédération Internationale de Football Association 2016), were observed. This category was employed to evaluate the extent to which teams used exercises similar to the FIFA 11+. Directly following the IPEP observation, the staff delivering the session (fitness coaches and physiotherapists) were asked to explain the reasons for choosing individual exercises. In cases where FIFA 11+ exercises were observed in modified forms, staff provided reasons for the modifications. The staff members' verbal responses were noted on the data collection sheet. Information on the use and modification of exercises was also gathered at regular staff team meetings.

\section{Analysis}

The data from all four teams were combined for analysis. For each individual FIFA 11+ exercise, the proportions of the 160 observed IPEP sessions in which the exercise was "performed", "performed modified", and "not performed", were calculated using Microsoft Excel $^{\mathrm{TM}}$. The reasons for including, excluding, and modifying each exercise, as provided by staff members, were entered into a table, structured on the components of the FIFA 11+. The number of staff members providing each reason was calculated.

\section{Results}

One hundred and sixty IPEP sessions were observed, which represented $36 \%$ of the total number of IPEP sessions performed by the teams across the season and $16 \%$ of the total training sessions (in any form) performed by the teams.

\section{Use of individual FIFA $11+$ exercises}

The proportion of total IPEP sessions in which each FIFA 11+ exercise was coded as "performed", "performed modified", and "not performed" are summarized in Figure 1. The exercises are labeled as in the original FIFA $11+$ (http://www.f-marc.com/downloads/posters_generic/english.pdf) and are ranked from left to right in descending order of the proportion performed in original form. The average proportion of sessions in which individual FIFA 11+ exercises were performed in original form was $12 \%$ (range across the different exercises 0-33\%). The corresponding figure for exercises performed in modified form was $28 \%$ (range 2-62\%), and for exercises not performed $61 \%$ (range $28-98 \%$ ).

The five most frequently observed FIFA 11+ exercises in their original form, were the "sideways bench" (33\%), followed by the "bench", "hip in", "hip out" (each 28\%), and "running quick forward \& back" (11\%) (Fig. 1). The five most frequently observed exercises in modified form were the "“"single-leg stance" (62\%), "squats" (60\%), "running straight" (60\%), "bench" (44\%), and "jumping" $(43 \%)$ (Fig. 1). The five most frequently observed exercises, in either original or modified form, were the "bench" (72\%), "squats" (69\%), "running straight" (68\%), "single-leg stance" (66\%), and "sideways bench" (64\%).

Staff input regarding reasons for the use and modification of individual exercises

The reasons for including, excluding or modifying individual FIFA 11+ exercises, including examples of modifications, are summarized in Table 1. Staff members could provide more than one reason in each category. The number of staff members (from the total of nine fitness coaches and physiotherapists) providing each reason is shown in brackets.

The most frequently provided reasons for modifying exercises were to add variation, progression, challenge, and individualization. Staff perceived these factors to be important for motivating players, avoiding boredom and tailoring the exercises to the different ability levels and situations of individual players. For example, exercises were often modified for players who had recently joined the team or had recently returned to the team following an absence due to injury, illness, or national team participation. Another frequently reported reason for modification was to align the preventive exercises with athletic training goals (e.g., strength and speed) and cognitive training goals (e.g. reaction time and peripheral awareness). For example, squats were performed with added weight to develop strength and players were challenged to react to visual or auditory cues during balance exercises, to add a cognitive challenge (Huijgen et al., 2015).

The first and last sections of the FIFA $11+$, the "running exercises", were perceived by staff members as a valuable part of soccer training warm-ups. However, these exercises were considered to be less relevant when the IPEP delivery format was not a warm-up. Particular running exercises (e.g., circling partner, shoulder contact) were often omitted due to the overlap with drills in the (coach-led) technical and tactical sections of soccer training, which involved similar movements and challenges, but with added soccer specificity. In general, the exercises in the middle section of the FIFA 11+, "strength, plyometric and balance" were highly valued by the staff members, who cited their strong evidence-base and relevance to athletic goals. It was emphasized that the volume and intensity of strength and jumping exercises required careful coordination with the volume and intensity of the overall soccer training, along with consideration of 


\section{O'Brien et al.}

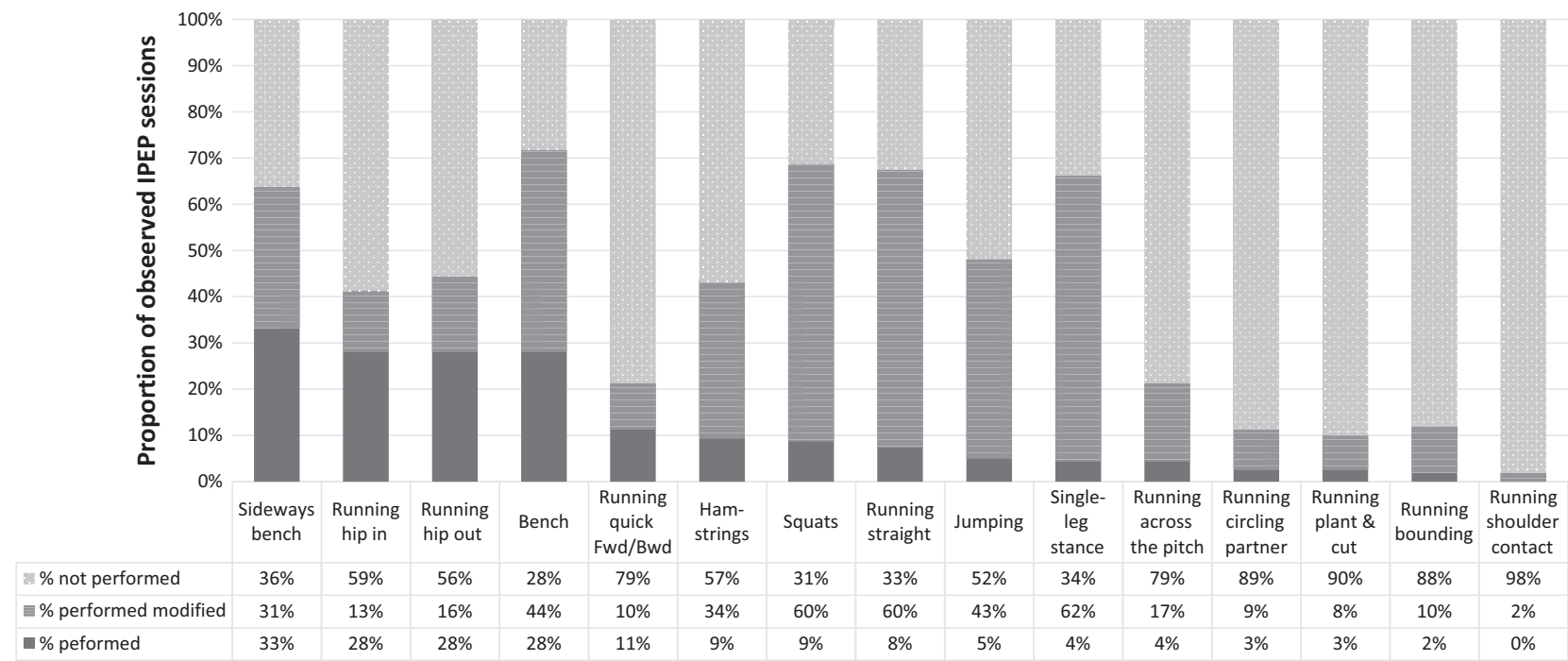

Fig. 1. The proportion of injury prevention exercise sessions $(n=160)$ in which individual FIFA $11+$ exercises were performed, performed modified or not performed by four professional youth soccer teams 1 .

its timing within the training week, in order to appropriately manage the total physiological load on players. This was particularly challenging in phases of the season with heavy game schedules, in which staff were cautious of player fatigue and overload.

\section{Discussion}

This is the first study to assess professional youth soccer teams' chosen injury prevention exercises against the industry-standard FIFA $11+$ program. The FIFA $11+$ exercises were observed more frequently in modified form (average $28 \%$ of sessions) than in their original form (average $12 \%$ of sessions). Staff modified exercises to add variation, progression, challenge, and individualization, as well as to tailor the exercises to specific athletic and cognitive training goals. This information is important for the ongoing development and delivery of future IPEPs, specifically tailored to this context.

The FIFA 11+ represents an efficacious injury prevention exercise program, backed by extensive supporting material and dissemination efforts (Bizzini \& Dvorak, 2015). However, the program's ultimate real-world impact depends not only on its efficacy (established in RCTs), but also on the extent to which soccer teams adopt and maintain the exercises it contains. When teams modify FIFA $11+$ exercises, there is need to understand why they do so, and to consider whether these modifications might impact (either positively or negatively) on the effectiveness of

\footnotetext{
${ }^{1}$ Images and descriptions of the FIFA $11+$ exercises are available at http://www.f-marc.com/downloads/posters_generic/english.pdf. The exercises are ranked from left to right in descending order of the $\%$ performed.
}

the program. Recent sports injury research emphasizes that enhancing the implementation of interventions necessitates a detailed understanding of both the individuals delivering the programs, and their specific delivery contexts (Finch \& Donaldson, 2010; Saunders et al., 2010; Padua et al., 2014; Twomey et al., 2015; Donaldson et al., 2016). This present study represents an important contribution to describing how, and why, staff members in professional youth soccer teams modify individual IPEP exercises to fit their context. The study's main strengths are the high number of prospectively recorded direct observations, standardized documentation and use of the industry standard IPEP for amateur soccer, the FIFA 11+, as the gold standard comparator.

Five FIFA 11+ exercises ("bench", "squats", "running straight", "single-leg stance", and "sideways bench") were observed, either in original or modified form, in well over half of the IPEP sessions. This aligns with the results of other recent studies, suggesting that certain FIFA 11+ components hold relevance for professional soccer teams (McCall et al., 2014; O'Brien et al., 2016). Importantly, this present study also details the reasons why staff members included, excluded or modified exercises, hence providing novel insights into how IPEPs and their components are adapted to fit a particular implementation context.

Taken together, the above results suggest that IPEPs for professional youth soccer can be structured on the same basic components as the FIFA $11+$ (e.g., strength, balance, core stability, and plyometrics), but require tailoring to the delivery context and a high degree of adaptability. Professional youth soccer teams have access to extensive training equipment and the support of multiple staff members. In 
Injury prevention in professional youth soccer

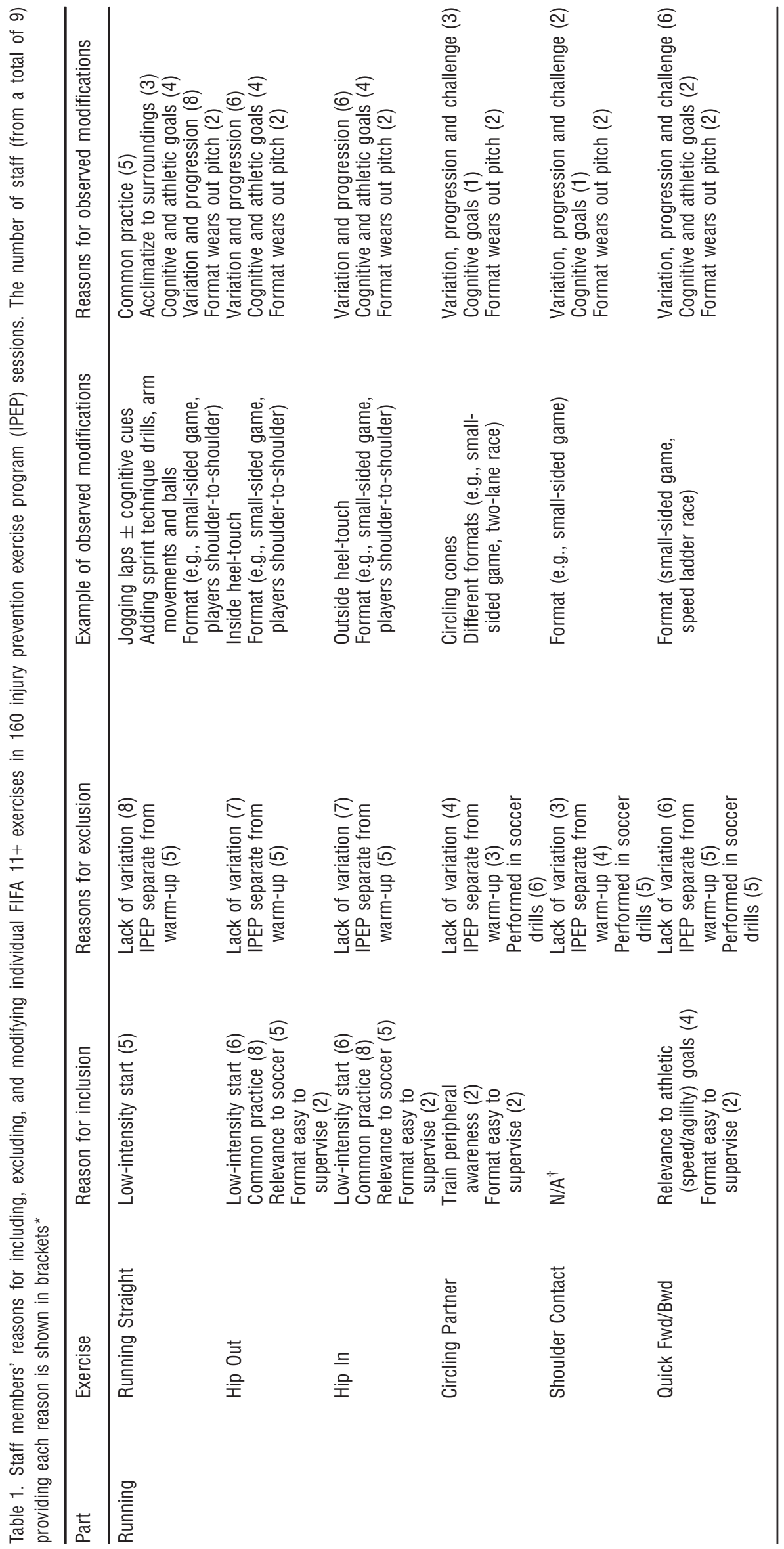




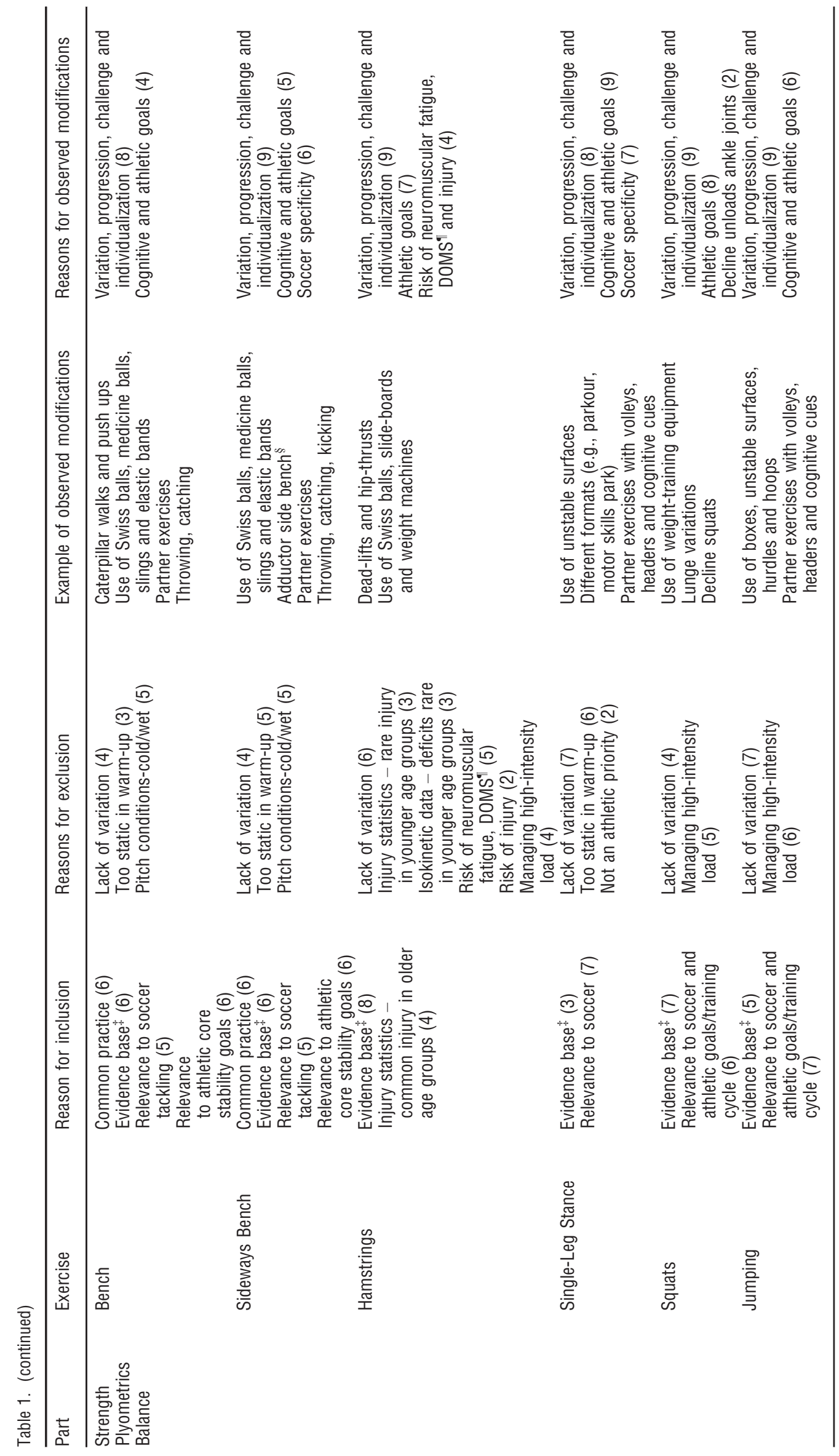


Injury prevention in professional youth soccer

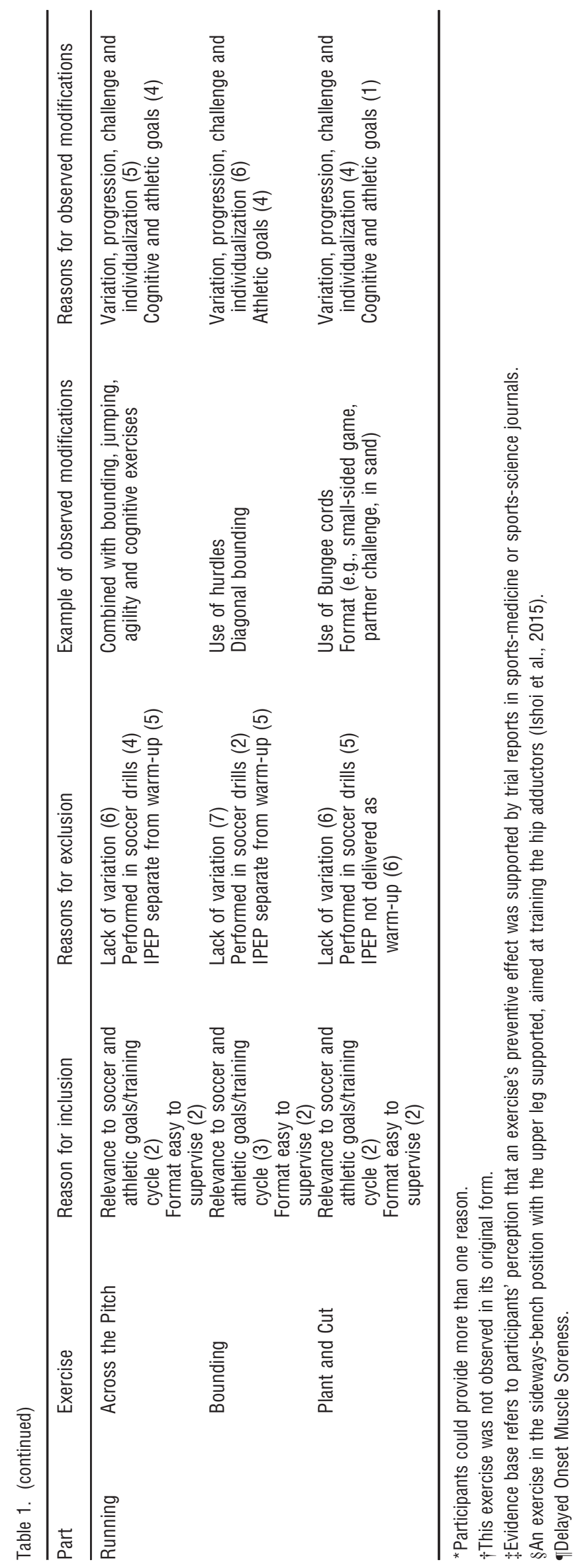




\section{O'Brien et al.}

this context, IPEPs are delivered by educated fitness coaches and physiotherapists, with an awareness of the published literature relating to injury prevention in soccer. These individuals require IPEPs with more variation, progression, challenge, and individualization than standard programs such as the FIFA 11+. In view of their specific implementation context, the staff of professional youth teams would perhaps be better served by clear, evidence-based guidelines on the essential ingredients of IPEPs that provide sufficient flexibility regarding the delivery format, location and selection of individual exercises.

In the field of implementation science, the concept of a program's core intervention components is wellestablished. Fixsen et al. (2005) defined these as the aspects of a program which are essential and indispensable in achieving the desired outcome. When translating evidence-based interventions to different real-world settings and populations, the core implementation components need to be upheld, whereas other, less essential aspects of the program can be tailored to better fit the local context. Applying this concept to the FIFA 11+, it can be hypothesized that the program's core intervention components are the elements of strength, balance, core stability and plyometrics. It is noteworthy that other IPEPs, containing similar components to the FIFA $11+$, but different individual exercises, have also demonstrated efficacy in large-scale RCTs (Mandelbaum et al., 2005; Emery \& Meeuwisse, 2010; Waldén et al., 2012). This supports the notion that, as long as core components are maintained, a certain degree of exercise modification is possible without jeopardizing an IPEP's injury prevention effect. Two recent systematic reviews and meta-analyses both found strong evidence for the preventive effect of IPEPs, while also identifying specific program components which appeared particularly important in achieving success (Lauersen et al., 2014; Rössler et al., 2014). In a review of studies with heterogeneous populations and interventions, Lauersen et al. (2014) identified strength and balance components as being particularly important to the success of IPEPs. The second review, focussing more specifically on IPEPs in athletes under 19 years of age (Rössler et al., 2014), concluded that IPEPs can reduce injuries by around $46 \%$, with those programs including jumping exercises appearing most effective.

In addition to establishing which core elements should be included in the content of IPEPs, there is a pressing need to define the essential aspects of successful IPEP delivery and support. These have been referred to, in the field of implementation science, as "core implementation components" (Fixsen et al., 2005), and typically relate to aspects of the staff who deliver interventions and organizational support. Unfortunately, many published reports on IPEPs in team ball sports fail to identify IPEP deliverers
(O'Brien \& Finch, 2014b) and other key implementation aspects (O'Brien \& Finch, 2014a). The results of this present study highlight important aspects relating to the staff delivery of IPEPs in professional youth soccer. As fitness coaches are the primary deliverers in this context, the success of programs will be influenced by the injury prevention beliefs, training goals and planned training cycles of these individuals. The direct input of staff members in this study suggests that IPEPs which harmonize with athletic training goals and which contain a high level of variation, progression, and individualization, will be more likely to be implemented in professional youth soccer settings.

\section{Study limitations}

As this study was conducted in the specific realworld context of one professional soccer academy, care is warranted in extrapolating the results to other populations and settings. Although a high number of IPEP sessions were observed, over multiple time points, only one author performed the observations and the coding of FIFA 11+ exercises as "performed", "performed modified" or "not performed" proved challenging at times. Although IPEP sessions were randomly selected for observation, only onethird of the teams' total IPEP sessions were observed and it is possible that the behavior of the teams differed in the unobserved sessions. This study focussed on injury prevention exercises, but other injury prevention strategies, including managing match and training load, are also important considerations in professional football (McCall et al., 2014). As both the number of staff members present at each IPEP session, and the frequency in which individual exercises were performed, varied considerably, it is possible that the reasons for exercise use and modification were not equally represented across individual staff members or individual FIFA 11+ exercises. The data collection sheet did not undergo formal validity or reliability testing (beyond face validity), but was structured on industry-standard, FIFA 11+ program.

\section{Future research}

As IPEP deliverers frequently use modifications of established exercises, there is a need to establish which aspects of programs represent the essential core intervention components, as opposed to the non-essential aspects which can be modified without jeopardizing program fidelity. In view of the challenge of implementing IPEPs alongside heavy game schedules and other training priorities, there is need to define the minimum dosage of core IPEP components that is needed to achieve (and maintain) injury prevention effects. In implementation science, this is known as the adaptation vs fidelity challenge (Fortington et al., 2015). 
Injury prevention in professional youth soccer

\section{Perspectives}

This study adds to a growing body of recently published research (Lindblom et al., 2014; Fortington et al., 2015; Frank et al., 2015; Donaldson et al., 2016) highlighting the key role of successful implementation in preventing sports injuries. Employing the industrystandard FIFA 11+ program for amateur soccer as the comparator, the findings shed light on the use and modification of injury prevention exercises in professional youth soccer. The direct observations of IPEPs, in combination with input from staff members, demonstrates how and why end-users modify program to fit their specific context. This information will inform both researchers and practitioners aiming to enhance the real-world impact of IPEPs in professional soccer settings, while also holding relevance for IPEP implementation in other team ball sport settings.

Key words: Sport, injuries, training.

\section{Funding}

J. O. is supported by a Federation University Australia PhD Scholarship. C. F. F. is supported by an
NHMRC Principal Research Fellowship (ID: 1058737). The Australian Collaboration for Research into Injury in Sport and its Prevention (ACRISP) is one of the International Research Centres for Prevention of Injury and Protection of Athlete Health supported by the International Olympic Committee (IOC).

\section{Competing interests}

W. Y. and C. F. F. have no conflicts of interest that are directly relevant to the content of this article. $\mathrm{J}$. $\mathrm{O}$. is employed at the professional soccer academy involved in this study. It is possible that the author's relationship with academy staff influenced the results.

\section{Contributorship statement}

J. O. led this work as part of his $\mathrm{PhD}$ studies. $\mathrm{He}$ designed the study, led its conduct, had the major role in paper writing and is responsible for the overall content. W. Y. and C. F. F. contributed to the design of the study, analysis of data, and the writing of the article.

\section{References}

Al Attar WS, Soomro N, Pappas E, Sinclair PJ, Sanders RH. How effective are F-MARC injury prevention programs for soccer players? A systematic review and meta-analysis. Sports Med 2016: 46: 205-217.

Bahr R, Thorborg K, Ekstrand J. Evidence-based hamstring injury prevention is not adopted by the majority of Champions League or Norwegian Premier League football teams: the Nordic Hamstring survey. Br J Sports Med 2015: 49: 14661471.

Bizzini M, Dvorak J. FIFA 11+: an effective programme to prevent football injuries in various player groups worldwide-a narrative review. Br J Sports Med 2015: 49: 577-579.

Bizzini M, Junge A, Dvorak J. Implementation of the FIFA 11+ football warm up program: how to approach and convince the Football associations to invest in prevention. Br J Sports Med 2013: 47: 803-806.

Brink MS, Visscher C, Arends S, Zwerver J, Post WJ, Lemmink KA. Monitoring stress and recovery: new insights for the prevention of injuries and illnesses in elite youth soccer players. Br J Sports Med 2010: 44: 809-815.

Donaldson A, Lloyd DG, Gabbe BJ, Cook J, Finch CF. We have the programme, what next? Planning the implementation of an injury prevention programme. Inj Prev 2016: doi: 10.1136/injuryprev-2015041737.

Emery CA, Meeuwisse WH. The effectiveness of a neuromuscular prevention strategy to reduce injuries in youth soccer: a cluster-randomised controlled trial. Br J Sports Med 2010: 44: 555-562.

Fédération Internationale de Football Association. Commentary on the regulations for the status and transfer of players. Fédération Internationale de Football Association, 2007.

Fédération Internationale de Football Association. FIFA $11+$ a complete warm-up programme. Fédération Internationale de Football Association, 2016.

Finch C. A new framework for research leading to sports injury prevention. J Sci Med Sport 2006: 9: 3-9.

Finch CF, Donaldson A. A sports setting matrix for understanding the implementation context for community sport. Br J Sports Med 2010: 44: 973-978.

Fixsen DL, Naoom SF, Blase KA, Friedman RM, Wallace F. Implementation research: a synthesis of the literature. The National Implementation Research Network (FMHI Publication \#231): Tampa, FL: University of South Florida, Louis de la Parte, 2005.

Fortington LV, Donaldson A, Lathlean T, Young WB, Gabbe BJ, Lloyd D, Finch CF. When 'just doing it' is not enough: assessing the fidelity of player performance of an injury prevention exercise program. J Sci Med Sport 2015: 18: 272-277.

Frank BS, Register-Mihalik J, Padua DA. High levels of coach intent to integrate a ACL injury prevention program into training does not translate to effective implementation. J Sci Med Sport 2015: 18: 400-406.

Hägglund M, Atroshi I, Wagner P, Waldén M. Superior compliance with a neuromuscular training programme is associated with fewer ACL injuries and fewer acute knee injuries in female adolescent football players: secondary analysis of an RCT. Br J Sports Med 2013: 47: 974-979. 


\section{O'Brien et al.}

Hammes D, Aus der Funten K, Kaiser S, Frisen E, Bizzini M, Meyer $T$. Injury prevention in male veteran football players - a randomised controlled trial using "FIFA 11+". J Sports Sci 2015: 33: 873-881.

Huijgen BC, Leemhuis S, Kok NM, Verburgh L, Oosterlaan J, ElferinkGemser MT, Visscher C. Cognitive functions in elite and sub-elite youth soccer players aged 13 to 17 years. PLoS ONE 2015: 10(12): e0144580.

Ishoi L, Sorensen CN, Kaae NM, Jorgensen LB, Holmich P, Serner A. Large eccentric strength increase using the Copenhagen Adduction exercise in football: a randomized controlled trial. Scand J Med Sci Sports 2015: doi: 10.1111/sms.12585.

Junge A, Rosch D, Peterson L, GrafBaumann T, Dvorak J. Prevention of soccer injuries: a prospective intervention study in youth amateur players. Am J Sports Med 2002: 30: 652-659.

Lauersen JB, Bertelsen DM, Andersen LB. The effectiveness of exercise interventions to prevent sports injuries: a systematic review and meta-analysis of randomised controlled trials. Br J Sports Med 2014: 48: 871-877.

Lindblom H, Waldén M, Carlfjord S, Hägglund M. Implementation of a neuromuscular training programme in female adolescent football: 3-year follow-up study after a randomised controlled trial. Br J Sports Med 2014: 48: 1425-1430.

Mandelbaum BR, Silvers HJ, Watanabe DS, Knarr JF, Thomas SD, Griffin LY, Kirkendall DT, Garrett W. Effectiveness of a neuromuscular and proprioceptive training program in preventing anterior cruciate ligament injuries in female athletes: 2-year follow-up. Am J Sports Med 2005: 33: 1003-1010.

McCall A, Carling C, Nedelec M, Davison M, Le Gall F, Berthoin S, Dupont G. Risk factors, testing and preventative strategies for noncontact injuries in professional football: current perceptions and practices of 44 teams from various premier leagues. Br J Sports Med 2014: 48: 1352-1357.

O'Brien J, Finch CF. The implementation of musculoskeletal injury-prevention exercise programmes in team ball sports: a systematic review employing the REAIM framework. Sports Med 2014a: 44: 1305-1318.

O'Brien J, Finch CF. A systematic review of core implementation components in team ball sport injury prevention trials. Inj Prev 2014b: 20: 357-362.

O'Brien J, Finch CF. Injury prevention exercise programmes in professional youth soccer: understanding the perceptions of programme deliverers. BMJ Open Sport Exerc Med 2016a: 2: 10.1136/bmjsem-2015-000075.

O'Brien J, Finch CF. Injury prevention exercise programs for professional soccer: understanding the perceptions of the end-users. Clin J Sport Med 2016b: doi: 10.1097/JSM.000000000 0000291

O'Brien J, Young W, Finch CF. The delivery of injury prevention exercise programmes in professional youth soccer: comparison to the FIFA 11+. J Sci Med Sport 2016: doi: 10.1016/j.jsams.2016.05.007.

Owoeye OB, Akinbo SR, Tella BA, Olawale OA. Efficacy of the FIFA $11+$ warm-up programme in male youth football: a cluster randomised controlled trial. J Sports Sci Med 2014: 13: 321-328.

Padua DA, Frank B, Donaldson A, de la Motte S, Cameron KL, Beutler AI, DiStefano LJ, Marshall SW. Seven steps for developing and implementing a preventive training program: lessons learned from JUMP-ACL and beyond. Clin Sports Med 2014: 33: 615-632.

Pfirrmann D, Ingelfinger P, Simon P, Tug S. Analysis of injury incidences in male professional adult and elite youth soccer players: a systematic review. J Athl Train 2016: 51(5): 410-424.

Price RJ, Hawkins RD, Hulse MA, Hodson A. The Football Association medical research programme: an audit of injuries in academy youth football. Br J Sports Med 2004: 38: 466-471.

Rössler R, Donath L, Bizzini M, Faude O. A new injury prevention programme for children's football FIFA 11+ Kids - can improve motor performance: a cluster-randomised controlled trial. J Sports Sci 2016: 34: 549-556.
Rössler R, Donath L, Verhagen E, Junge A, Schweizer T, Faude O. Exercise-based injury prevention in child and adolescent sport: a systematic review and meta-analysis. Sports Med 2014: 44: 1733-1748.

Saunders N, Otago L, Romiti M, Donaldson A, White P, Finch C. Coaches' perspectives on implementing an evidence-informed injury prevention programme in junior community netball. Br J Sports Med 2010: 44: 1128-1132.

Silvers-Granelli H, Mandelbaum B, Adeniji O, Insler S, Bizzini M, Pohlig R, Junge A, Snyder-Mackler L, Dvorak J. Efficacy of the FIFA $11+$ injury prevention program in the collegiate male soccer player. Am J Sports Med 2015: 43(11): 2628 2637.

Soligard T, Myklebust G, Steffen K, Holme I, Silvers H, Bizzini M, Junge A, Dvorak J, Bahr R, Andersen TE. Comprehensive warm-up programme to prevent injuries in young female footballers: cluster randomised controlled trial. BMJ 2008: 337: a2469.

Soligard T, Nilstad A, Steffen K, Myklebust G, Holme I, Dvorak J, Bahr R, Andersen TE. Compliance with a comprehensive warm-up programme to prevent injuries in youth football. Br J Sports Med 2010: 44: 787-793.

Steffen K, Emery CA, Romiti M, Kang J, Bizzini M, Dvorak J, Finch CF, Meeuwisse WH. High adherence to a neuromuscular injury prevention programme (FIFA 11+) improves functional balance and reduces injury risk in Canadian youth female football players: a cluster randomised trial. Br J Sports Med 2013: 47: 794-802.

Twomey DM, Doyle TL, Lloyd DG, Elliot BC, Finch CF. Challenges when implementing an evidencebased exercise injury prevention training program in community-level sport. J App Case Studies Sport Ex Sc 2015: 1: 29-39.

Waldén M, Atroshi I, Magnusson H, Wagner P, Hägglund M. Prevention of acute knee injuries in adolescent female football players: cluster randomised controlled trial. $\mathrm{BMJ}$ 2012: 344: e3042. 


\section{University Library}

\section{- M M I N E R VA A gateway to Melbourne's research publications}

Minerva Access is the Institutional Repository of The University of Melbourne

Author/s:

O'Brien, J;Young, W;Finch, CF

Title:

The use and modification of injury prevention exercises by professional youth soccer teams.

Date:

2017-11

Citation:

O'Brien, J., Young, W. \& Finch, C. F. (2017). The use and modification of injury prevention exercises by professional youth soccer teams.. Scand J Med Sci Sports, 27 (11), pp.1337-1346. https://doi.org/10.1111/sms.12756.

Persistent Link:

http://hdl.handle.net/11343/246641

License:

CC BY-NC-ND 